\title{
Gambaran Perilaku Hidup Bersih dan Sehat (PHBS) serta Tingkat Religiusitas pada Orang Lanjut Usia
}

\author{
Alidina Nur Afifah', Andhika Idam Radityo ${ }^{2}$ \\ 1) Departemen Kedokteran Komunitas, Fakultas Kedokteran dan Kesehatan, Universitas Muhammadiyah Jakarta \\ 2) Program Studi Kedokteran, Fakultas Kedokteran dan Kesehatan Universitas Muhammadiyah Jakarta \\ *Corresponding author: alidinanurafifah@umj.ac.id
}

\begin{abstract}
Background: Infectious diseases are still the cause of most deaths in the world so it is necessary to carry out prevention efforts that can minimize the impact on physical, psychological, and social aspects, especially for the elderly. Clean and healthy behaviour program (PHBS) is a program to control hygiene and prevent infectious disease. Religiosity is one of the factors of happiness and support for the life quality of the elderly. PHBS which is the manifestation of clean and healthy behavior which also contains vital religious values is the embodiment of one's religiosity and religious activities. The research objective was to determine the description of PHBS and religiosity level of the elderly in Pondok Jagung. Methods: This study was a cross-sectional descriptive quantitative research with 116 subjects. The instruments used were the PHBS Questionnaire and the Religiosity Level Questionnaire. Result: The results showed that 68 subjects $(58,6 \%)$ elderly in Pondok Jagung village had a good PHBS and 48 subjects $(41,4 \%)$ had sufficient PHBS and there were no subjects in the poor category. The level of religiosity of the elderly in Pondok Jagung village was 19 subjects (16.4\%) in the good category, 77 subjects (66.4\%) in the moderate category, and 20 subjects $(17.2 \%)$ in the bad category. Conclusion: more than half of the elderly are categorized as good PHBS and moderate level of religiosity in study population. Although dominated by good PHBS, these achievements are still below the 2016-2019 PHBS national target. It is necessary to do further research on the influence of the level of religiosity with the PHBS achievement.
\end{abstract}

Keywords: PHBS, Level of Religiousity, Elderly.

\begin{abstract}
ABSTRAK
Latar belakang: penyakit infeksi masih menjadi penyebab kematian terbanyak di dunia sehingga diperlukan upaya pencegahan yang dapat meminimalisir dampak terhadap aspek fisik, psikis, dan sosial terutama bagi orang lanjut usia (lansia). Salah satu program pemerintah dalam mengupayakan hal tersebut adalah program Perilaku Hidup Bersih dan Sehat (PHBS). Religiusitas dan aktivitas keagamaan menjadi salah satu faktor kebahagiaan dan pendukung terhadap kualitas hidup lansia. PHBS yang merupakan perwujudan perilaku bersih dan sehat juga mengandung nilai-nilai vital agama terhadap religiusitas dan aktivitas keagamaan seseorang. Tujuan: untuk mengetahui gambaran PHBS dan tingkat religiusitas lansia. Metode: penelitian ini adalah studi kuantitatif deskriptif dengan pendekatan cross sectional pada 116 responden. Instrumen penelitian yang digunakan adalah Kuesioner PHBS dan Kuesioner Tingkat Religiusitas. Hasil: penelitian menunjukkan bahwa 68 orang $(58,6 \%)$ lansia di kelurahan Pondok Jagung memiliki PHBS yang baik dan 48 orang $(41,4 \%)$ memiliki PHBS cukup dan tidak terdapat responden dengan kategori kurang. Tingkat religiusitas lansia di
\end{abstract}


kelurahan Pondok Jagung adalah 19 orang (16,4\%) berkategori baik, 77 orang $(66,4 \%)$ berkategori sedang, dan 20 orang $(17,2 \%)$ berkategori buruk. Kesimpulan: lebih dari separuh lansia di RW 01 dan 05 Kelurahan Pondok Jagung berkategori PHBS baik dan tingkat religiusitas sedang. Meskipun didominasi PHBS baik, namun capaian tersebut masih di bawah target capaian nasional PHBS 2016-2019. Perlu dilakukan penelitian lebih lanjut tentang pengaruh tingkat religiusitas dengan capaian PHBS tersebut.

Kata kunci: PHBS, Tingkat Religiusitas, Lansia.

\section{PENDAHULUAN}

Popularitas penyakit infeksi sebagai penyebab kematian tertinggi di dunia berdasarkan Global Health Estimates, World Health Organization (WHO) tidak setinggi penyakit noninfeksi lainnya. Dilaporkan dari 10 penyebab kematian tertinggi, terdapat 3 penyakit yang dikategorikan dengan penyakit infeksi yaitu infeksi saluran napas bawah, diare, dan tuberkulosis (1), namun fakta ini tidak mengecilkan berbagai dampak baik fisik, psikis, maupun sosial yang diakibatkan oleh terus bertambahnya insiden penyakit infeksi terutama bagi populasi lanjut usia (lansia) (2,3). Jumlah lansia di Indonesia yang terus meningkat hingga 9,6 persen dalam 5 dekade (1971-2019) membuat kualitas hidup lansia terutama pada aspek kesehatan menjadi salah satu fokus pemerintah (4,5). Salah satu upaya pencegahan yang dilakukan adalah dengan melakukan promosi kesehatan tentang Perilaku Hidup Bersih dan Sehat (PHBS) sebagai bagian dari program Gerakan Masyarakat Sehat (Germas) $(6,7)$.

Religiusitas merupakan upaya internalisasi unsur-unsur dasar agama bagi seorang individu, upaya tersebut mendorong perwujudan perilaku dan sikap yang diaplikasikan dalam keseharian $(8,9,10)$. Religiusitas dan aktivitas keagamaan menjadi salah satu faktor kebahagiaan dan pendukung terciptanya kualitas hidup lansia (11). PHBS yang merupakan perwujudan perilaku bersih dan sehat yang juga mengandung nilai-nilai vital agama merupakan pengejawantahan religiusitas dan aktivitas keagamaan seseorang di kehidupannya.

Kelurahan Pondok Jagung memiliki populasi lansia tertinggi di Kota Tangerang Selatan berada di bawah wilayah kerja Puskesmas Pondok Jagung yang memiliki program unggulan pelayanan prima dan peningkatan kualitas hidup masyarakat $(12,13)$. Perlu diketahui pelaksanaan PHBS dan tingkat religiusitas pada komunitas lansia sehingga menjadi gambaran bagi perencanaan program lanjutan dan kepentingan penelitian selanjutnya.

\section{METODE}

Jenis penelitian ini adalah penelitian kuantitatif deskriptif dengan desain cross sectional. Penelitian dilakukan di wilayah RW 01 dan 05 Kelurahan Pondok Jagung pada September-Desember 2019. Sampel penelitian diambil menggunakan metode total sampling dengan populasi seluruh lansia di tempat penelitian yaitu lansia di RW 01 dan 05 Kelurahan Pondok Jagung.

Data yang dipergunakan dalam penelitian ini adalah data primer. Pengumpulan data dilakukan oleh peneliti dengan menggunakan kuesioner yang sudah divalidasi. Instrumen penelitian yang digunakan adalah kuesioner PHBS yang terdiri dari 20 pertanyaan dan kuesioner religiusitas sebanyak 22 pertanyaan. 
Analisis data dilakukan secara univariat untuk menggambarkan variabel PHBS, tingkat religiusitas dan karakteristik responden. Penelitian ini telah melalui proses telaah etik dan mendapatkan persetujuan etik dengan nomor persetujuan 123 / PE / KE / FKK-UMJ / X / 2019.

\section{HASIL}

Analisis univariat karakteristik responden didapatkan data frekuensi distribusi dari jenis kelamin, status bekerja, tingkat pendidikan, status pernikahan, kebiasaan merokok, riwayat konsumsi alkohol, jumlah anak, dan tingkat penghasilan dengan gambaran sebagai berikut:

Tabel 1. Gambaran Karakteristik Responden

\begin{tabular}{|c|c|c|}
\hline $\begin{array}{l}\text { Karakteristik } \\
\text { Responden }\end{array}$ & $\begin{array}{l}\text { Frekuensi } \\
\text { (n) }\end{array}$ & $\begin{array}{c}\text { Persentase } \\
(\%)\end{array}$ \\
\hline \multicolumn{3}{|l|}{ Jenis kelamin } \\
\hline Laki-laki & 57 & 49,1 \\
\hline Perempuan & 59 & 50,9 \\
\hline \multicolumn{3}{|l|}{ Status Bekerja } \\
\hline Bekerja & 55 & 47,4 \\
\hline Tidak Bekerja & 61 & 52,6 \\
\hline \multicolumn{3}{|l|}{ Tingkat } \\
\hline \multicolumn{3}{|l|}{ Pendidikan } \\
\hline SMA & 12 & 10,3 \\
\hline SMP & 17 & 14,7 \\
\hline $\mathrm{SD}$ & 71 & 61,2 \\
\hline Tidak Sekolah & 16 & 13,8 \\
\hline \multicolumn{3}{|l|}{ Status Pernikahan } \\
\hline \multirow[t]{2}{*}{ Duda/Janda } & 87 & 75 \\
\hline & 29 & 25 \\
\hline \multicolumn{3}{|l|}{ Kebiasaan } \\
\hline \multicolumn{3}{|l|}{ Merokok } \\
\hline Tidak Merokok & 78 & 67,2 \\
\hline Merokok & 38 & 32,8 \\
\hline \multicolumn{3}{|l|}{ Riwayat Konsumsi } \\
\hline \multicolumn{3}{|l|}{ Alkohol } \\
\hline \multicolumn{3}{|l|}{ Konsumsi } \\
\hline \multirow[t]{2}{*}{ Tidak Konsumsi } & 0 & 0 \\
\hline & 116 & 100 \\
\hline \multicolumn{3}{|l|}{ Jumlah Anak } \\
\hline Sedikit Anak & 79 & 68,1 \\
\hline Banyak Anak & 31 & 26,7 \\
\hline Tidak Ada Anak & 6 & 5,2 \\
\hline \multicolumn{3}{|l|}{ Tingkat } \\
\hline \multicolumn{3}{|l|}{ Penghasilan } \\
\hline Tinggi & 27 & 23,3 \\
\hline Rendah & 89 & 76,7 \\
\hline
\end{tabular}

Analisis univariat dilakukan terhadap gambaran variabel PHBS dengan kategori baik, cukup, dan kurang serta variabel tingkat religiusitas dengan kategori baik, sedang, dan buruk didapatkan data sebagai berikut:

Tabel 2. Gambaran PHBS dan Tingkat Religiusitas

\begin{tabular}{lcc}
\hline \multicolumn{1}{c}{ Variabel } & $\begin{array}{c}\text { Frekuensi } \\
(\mathbf{n})\end{array}$ & $\begin{array}{c}\text { Persentase } \\
(\%)\end{array}$ \\
\hline PHBS & & \\
$\quad$ Baik & 68 & 58,6 \\
Cukup & 48 & 41,4 \\
$\quad$ Kurang & 0 & 0 \\
Tingkat & & \\
Religiusitas & & \\
$\quad$ Baik & 19 & 16,4 \\
Sedang & 77 & 66,4 \\
Buruk & 20 & 17,2 \\
\hline
\end{tabular}

\section{PEMBAHASAN}

Persentase jenis kelamin yang relatif seragam yaitu 57 orang $(49,1 \%)$ untuk lakilaki dan 59 orang $(50,9 \%)$ untuk perempuan dapat menjadi gambaran superfisial bagi kita dalam menarik simpulan representasi hasil penelitian yang cukup baik terhadap responden laki-laki maupun perempuan. Jumlah responden yang bekerja dan tidak bekerja juga relatif sama dengan jumlah 55 orang $(47,4 \%)$ dan 61 orang $(52,6 \%)$. Sebagian besar responden masih dalam status pernikahan yaitu sebesar 87 orang (75\%) dan hanya seperempat responden saja yang sudah tidak hidup dengan pasangannya yaitu 29 orang (25\%) sehingga mayoritas responden lansia masih memiliki support system yang baik yaitu keberadaan keluarga terutama orang terdekat yaitu suami atau istri yang dapat mendukung upaya teknis dan psikis dalam mewujudkan PHBS dan tingkat religiusitas yang baik (18). Hal ini juga didukung oleh data yang menunjukkan bahwa sebagian besar responden lansia memiliki sejumlah 
anak yang juga menjadi bagian dari support system tersebut sedangkan hanya sebagian kecil saja yang tidak memiliki anak yaitu 6 orang $(5,2 \%)$. Kesadaran dalam menjaga kesehatan tubuh responden cukup baik yang hal ini digambarkan dari banyaknya responden yang memiliki kebiasaan tidak merokok yaitu sebesar 78 orang $(67,2 \%)$ dan seluruh responden tidak mengonsumsi alkohol 116 orang (100\%).

Hasil penelitian menunjukkan bahwa jumlah responden yang memiliki PHBS baik yaitu 68 orang $(58,6 \%)$, sehingga dapat diartikan bahwa sebagian besar responden telah menerapkan PHBS yaitu menggunakan air bersih, mencuci tangan dengan air bersih dan sabun, menggunakan jamban sehat, memberantas jentik di rumah, makan buah dan sayur setiap hari, melakukan aktivitas fisik setiap hari serta tidak merokok di dalam rumah $(6,15)$. Sejalan dengan hasil tersebut, Program pengembangan lansia di Puskesmas Pondok Jagung seperti kegiatan penyuluhan kesehatan, pengukuran tekanan darah, pengecekan kadar gula darah sewaktu, penyelenggaraan posbindu lansia yang dilaksanakan di hari Jumat setiap pekan yang seluruhnya terus ditingkatkan dan dievaluasi (19). Penelitian selanjutnya perlu mengukur keterkaitan antara upaya pengembangan program tersebut dengan tingginya gambaran PHBS ini. Tujuan pemerintah menggalakkan program PHBS sebagai upaya meningkatkan kualitas kesehatan dan memiliki bekal pengetahuan dan kesadaran dalam menjalani perilaku hidup yang mendukung kesejahteraan diri. Tingkat pendidikan yang terbilang rendah dengan mayoritas responden berpendidikan SD sebanyak 71 orang $(61,2 \%)$ tidak membuat pelaksanaan PHBS ini terhambat.

Hasil penelitian menunjukkan bahwa sebagian responden memiliki tingkat religiusitas sedang yaitu berjumlah77 orang $(66,4 \%)$. Religiusitas merupakan salah satu faktor penentu kualitas kehidupan manusia. Keakraban seorang manusia dengan Penciptanya dapat dilihat dari religiusitasnya (20). Tingkat religiusitas yang cukup baik dengan kategori sedang ini sejalan dengan pelaksanaan PHBS yang baik pula. Pada dasarnya komponen dalam PHBS merupakan praktik dari nilai-nilai agama seperti kebersihan sebagaimana termaktub dalam Al-Quran surah AlMudatsir ayat 74 yang artinya "...dan bersihkanlah pakaianmu dan tinggalkanlah segala macam kotoran". Begitu pula dalam hadits Rasulullah Shallallahu 'alaihi wa sallam (SAW) yang mengajarkan untuk senantiasa berperilaku bersih dengan mandi secara rutin yaitu "Adakah merupakan hak atas seseorang muslim ketika mandi dalam seminggu, agar sehari daripadanya ia membasahi kepala dan seluruh badannya" (Muttafaqun 'Alaih). Aspek anjuran melakukan cuci tangan dalam komponen PHBS juga relevan dengan perintah Rasulullah SAW yaitu untuk mencuci tangan sebelum tidur, saat bangun tidur, serta sebelum dan sesudah menjenguk orang sakit $(21,22)$.

\section{KESIMPULAN}

Gambaran PHBS di RW 01 dan RW 05 kelurahan Pondok Kacang baik dan tingkat religiusitasnya sedang. Tingkat religiusitas dan karakteristik responden merupakan faktor yang berpengaruh pada PHBS sehingga perlu dilakukan analisis terkait relevansi hasil tingkat religiusitas dengan mayoritas kategori sedang dan juga faktor yang berpengaruh pada PHBS lansia berangkat dari gambaran yang didapatkan dalam penelitian ini sehingga dapat menjadi acuan yang jelas untuk mendukung 
penentuan kebijakan bagi pemerintah setempat.

\section{UCAPAN TERIMAKASIH}

Terimakasih kepada Fakultas Kedokteran dan Kesehatan Universitas Muhammadiyah Jakarta, Puskesmas Pondok Jagung, Dinas Kesehatan Kota Tangerang Selatan, dan Pimpinan Wilayah Kelurahan Pondok Jagung dan RW 01 dan 05 Kelurahan Pondok Jagung yang telah membantu proses terlaksananya penelitian ini juga seluruh pihak yang telah berperan dalam penyelesaian publikasi.

\section{KONFLIK KEPENTINGAN}

Penulis menyatakan tidak memiliki konflik kepentingan, dengan pihak apapun yang dapat menimbulkan konflik etik atau sejenisnya.

\section{REFERENSI}

1. World Health Organization. The Top 10 Cause of Death [Internet]. Global Health Estimates. 2018 [cited 2020 Oct 15]. Available from: https://www.who.int/newsroom/fact-sheets/detail/the-top-10causes-of-death.

2. Bloom DE, Cadarette D. Infectious Disease Threats in the Twenty-First Century: Strengthening the Global Response. Front Immunol. 2019;10:549.

3. Yoshikawa TT, Norman DC. Geriatric Infectious Diseases: Current Concepts on Diagnosis and Management. Am Geriatr Soc. 2017;65(3):631-41.

4. Badan Pusat Statistik. Statistik Penduduk Lanjut Usia 2019. 042201905. 2019;1-258.

5. Kementerian Kesehatan Republik Indonesia. Rencana Aksi Nasional Kesehatan Lanjut Usia 2016-2019. Indonesia; 2016 p. 1-98.

6. Kementerian Kesehatan Republik
Indonesia. Pedoman Pembinaan Perilaku Hidup Bersih dan Sehat. Indonesia; 2011 p. 1-73.

7. Kementerian Kesehatan Republik Indonesia. Panduan Gerakan Masyarakat Hidup Sehat. 2016 p. 140.

8. Aviyah E, Farid M. Religiusitas, Kontrol Diri dan Kenakalan Remaja. Pers Jurnal Psikol Indonesia. 2014;3(2).

9. Hakim L. Internalisasi Nilai-Nilai Agama Islam dalam Pembentukan Sikap dan Perilaku Siswa Sekolah Dasar Terpadu Al-Muttaqin Kota Tasikmalaya. Jurnal Pendidik Agama Islam Ta'lim. 2012;10(1):67-77.

10. Rohman M, Hairudin. Konsep Tujuan Pendidikan Islam Perpektif Nilai-Nilai Sosial Kultural. Attadzkiyyah Jurnal Pendidik Islam. 2018;9(1):21-35.

11. Diponegoro AM, Mulyono $\mathrm{M}$. Faktor-Faktor Psikologis yang Mempengaruhi Kebahagiaan pada Lanjut Usia Suku Jawa di Klaten. Jurnal Bimbing dan Konseling. 2016;4(1).

12. Dinas Kesehatan Tangerang Selatan. Prevalensi Data Penyakit di Tangerang Selatan 2018. Tangerang Selatan; 2018.

13. Badan Pusat Statistik Kota Tangerang Selatan. Jumlah Penduduk 2017-2019 [Internet]. 2019. Available from: https://tangselkota.bps.go.id/indicat or/12/85/1/jumlah-penduduk.html

14. Notoatmodjo S. Metodologi Penelitian Kesehatan. Rineka Cipta; 2010.

15. Firmana AR. Gambaran Perilaku Hidup Bersih dan Sehat pada Lansia di Desa Kemukus Kecamatan Gombong Kabupaten Kebumen. Elibrary Stikes Muhammadiyah Gombong. 2016;

16. Nafa RA. Hubungan Tingkat Religiusitas dengan Tingkat Depresi 
Lansia Beragama Islam di Panti Tresna Werdha Budi Mulia 4 Margaguna Jakarta Selatan. Repos UIN Jakarta. 2015;

17. Prasetyo B, Jannah LM. Metode Penelitian Kuantitatif. Jakarta: Raja Grafindo Prasada; 2011. 274 p.

18. Handayani DY. Hubungan dukungan keluarga dengan penerapan perilaku hidup bersih dan sehat di Kelurahan Cisalak Pasar Cimanggis Kota Depok. Univ Indones Libr. 2013.

19. Puskesmas Pondok Jagung. Program Kerja Puskesmas Pondok Jagung 2019. Tangerang Selatan; 2019.

20. Satrianegara M. Pengaruh Religiusitas Terhadap Tingkat Depresi, Kecemasan, Stres, dan Kualitas Hidup Penderita Penyakit Kronis di Kota Makassar. Kaji Survei Epidemiologi Berbasis Integrasi Islam dan Kesehatan. 2014.

21. Anam K. Pendidikan Perilaku Hidup Bersih dan Sehat Menurut Perspektif Islam. Journal Sagacious. 2016;3(1):67-78.

22. Yanuarti E. Pengaruh Sikap Religiusitas Terhadap Perilaku Hidup Bersih dan Sehat Masyarakat Kabupaten Rejang Lebong. Journal Kaji Keislaman dan Kemasyarakatan. 2018;3(1). 